\title{
Finite element modelling of shot peening process- A progress overview
}

\author{
Y. H. Yang, M. Wan, W.H. Zhang \\ The Key Laboratory of Contemporary Design \& Integrated Manufacturing Technology, Ministry of Education, Northwestern Polytechnical Uni- \\ versity, P.O. Box 552, 710072 Xi'An, Shaanxi, China
}

Received 23 June 2008, Accepted 13 January 2009

\begin{abstract}
It is very significant to investigate the shot peening mechanism in ensuring a good resistance to fatigue and stress corrosion. This paper reviews the recent advancements in shot peening process. Emphasis is put on the application of numerical simulation techniques and finite element method in residual stress prediction during shot peening process. Different methods related to shot peening modelling and prediction of plastic deformation and surface integrity are reviewed. Some key issues such as algorithms and simulation procedures are discussed.
\end{abstract}

Key words: Shot peening; Finite element method; Compressive residual stress; Plastic deformations

\section{Introduction}

In order to achieve the final shape in metal forming, some structural panels must be formed by shot peening, which is a surface cold-working process usually employed to improve the fatigue strength of metallic part or members. Such a process is accomplished by bombarding the surface of the members with small spherical shots made of hardened materials at high velocities. As a result of collision of a shot with the surface of a component, an indentation is created which is surrounded by a plastic region followed by an elastic zone. Subsequently, the recovery of elastic zone will produces a large compressive residual stress on the surface. This compressive residual stress field is highly effective in preventing premature failure under conditions of cyclic loading. Therefore, it is very useful to be able to predict the pattern and magnitude of the residual stress distribution near the surface after shot peening. For this reason, many research efforts have been focused on this issue.

\section{State of the art}

It is well recognized that the result of shot peening depends strongly upon the shot parameters such as shot size, density, shape, impact velocity, hardness etc., the target parameters such as initial yield stress, work hardening characteristics, hardness, strain-rate dependence etc. and the process parameters such as mass flow rate, air pressure, angle of attack, peening time etc. If the related parameters are not well chosen (e.g., large shot, over peening, high velocities, etc.), superficial defects such as overlaps, scales, micro-cracks and surface roughness imperfections may occur [1-4]. As a result, the strength of the treated part may be significantly decreased [5,6]. To ensure a better resistance to fatigue and stress corrosion, the quantitative relationships between these parameters and residual stress characteristics must be established.

Numerous experimental studies have been attempted to evaluate the residual stress distribution, fatigue life and the influence of shot, target and process parameters [7-9]. The evaluation, however, is both time-consuming and cost- expensive. Besides, because the research is based on the specific designed target, it would not allow a careful examination of the effect of the parameters on the residual stress pattern.

To study the shot peening process quantitatively, a theoretical shot peening model was firstly proposed by Guechichi et al. [10] based on the simplified method of elastic plastic calculations of Zarka and Casier [11]. Guechichi’s model was further improved by Khabou et al. [12] and Fathallah et al. [13]. The above works [10,12,13] have the advantage taking into account the majority of controlling process parameters have been taken into account. Based on a new model of spherical cavity expansion, Al-Obaid [14] developed a number of theoretical expressions for the process parameters to study the residual stress distribution in the target. Kobayashi et al. [15] investigated the mechanism of compressive residual stress in shot peening by performing static compression tests and dynamic impact tests using a single steel ball against a flat steel plate. Besides, other authors [16-18] have developed simple theoretical schemes to analyze the shot peening process. Those analytical approaches principally lead to determine the residual stresses and the plastic deformations induced in the first affected layers of the shot peened part.

With the appearances of powerful finite element software such as ABAQUS, ANSYS and NASTRAN, attention was focused on numerical simulation of shot peening process [19-38]. Such a simulation method provides a cheap and easy way to study the dynamic impact of a shot with high velocity, the double non-linearity of the problem due to the contact of two bodies and the elastic-plastic behaviour of the target, etc.

Hardy et al. [19] used the FE method to solve the contact problem of a rigid sphere indenting an elastic-perfect plastic half-space for the first time. The first numerical analysis of shot peening using the commercial FE code was carried out by Edberg et al. [20], who simulated a single shot impacting visco-plastic and elasto-plastic materials but the parameters used in their study do not represent realistic peening parameters. The numerical simulation procedures of single and multiple shot impacts on a target have been developed by AlHassani et al. [21], Deslaef and Rouhaud [25,26]. Al- 
Hassani et al. [21] examined single shot impact with an incident angle whereas Deslaef et al. [25,26] examined the effect of rigid and deformable shot by comparing with experimental measurements. Both works, however, showed some differences.

To improve the modelling accuracy, dynamic analysis of single and multiple shot impacts have been conducted by many researchers [33-38]. Johnson [33] initially developed a dynamic model of a single shot using a pseudo-dynamic approach. In this approach, only the inertial properties of the shot were considered. As a result, a relationship between the depth of the plastic zone and the shot parameters, such as radius, mass and velocity, was obtained. This relationship was later validated by Clausen [34] and Iida [35]. Edberg et al. [36] conducted dynamic three-dimensional finite element analysis of a single shot impinging viscoplastic and elastoplastic materials with multi-linear isotropic strain-hardening and a strain rate scale factor. Meguid et al. [37,38] presented a systematic study of shot peening process based on dynamic FE analysis accounting for the effect of some shot and target parameters. In Ref. [37], Meguid et al. developed a three-dimensional finite element dynamic model of single and twin shot impacts using rigid spherical shots and metallic targets. The examined results of the effects of shot velocity, size and shape and target characteristics on residual stress distribution indicated that the effects of shot parameters were more important than the strain-hardening rate of the target. In another work [38], results revealed that multiple shot impacts result in a more uniform residual stress and plastic strain distribution and that the separation distance between shots significantly influences the residual stress field.

It is worth noting that although above works [19-38] provide a powerful method for establishing quantitative relationships between shot and target parameters and residual stress characteristics, FE methods could not still simulate a stream of discrete shots impacting on a target. Recently, discrete element (DE) method has been adopted to simulate shot peening process by Han et al. [39-41]. In their work, a DE representation of shot was adopted and different contact interaction laws for shot-target collision were extensively studied with special attention given to the proper selection of the parameter values involved. Besides, the modelling of the residual stresses on crack propagation and on the stress relief during load service was also performed [42-45].

\section{Methodology}

\subsection{Mechanics of shot peening process [27]}

If the impact between two solids is completely elastic, the potential energy is totally transformed into returned kinetic energy. Whereas, if the contact is elastic-plastic, the potential energy is only partially transformed. If there are internal degrees of freedom such as temperature, vibrations, deformations etc., a part of the stream kinetic energy and internal energy can be transformed each other. Let us consider a shot with mass, $m$, impacting a semi-finite body at a velocity, $V_{\mathrm{i}}$, under an angle of impingement, $\alpha$, and returning at a velocity, $V_{i}$, under an angle, $\alpha$ ' (see Fig. 1 ). The impact can be characterized by a coefficient, $e_{\mathrm{r}}$, called the coefficient of restitution, which is calculated as the ratio of by the normal projec- tion of the return velocity to the normal projection of the stream velocity.

$$
e_{\mathrm{r}}=\frac{V_{\mathrm{r}} \sin \alpha^{\prime}}{V_{\mathrm{i}} \sin \alpha}
$$

Experimentally, it is shown that $e_{\mathrm{r}}$ depends on the conditions of the contact between the shot and the treated material, and the shot/material hardness ratio. It equals 1 for an elastic contact, 0 for a plastic contact and between 0 and 1 in the case of elastic-plastic contact.

During the shot peening process, the movement of the shot can be a sliding, an in depth penetration, a spin or a combination of these motions. In order to simplify the problem, the movement of the shot particles is supposed to be an in-depth penetration and the surface sliding was supposed to be negligible. Consequently, the energy restored in the plasticized first outer layers by the static indentation is equal to that restored by the dynamic impact.

In the case of normal impact, the difference between the initial and the restored kinetic energies is given by the following expression:

$$
\Delta W_{\left(\alpha=90^{\circ}\right)}=m V_{\mathrm{i}}^{2}\left(1-e_{\mathrm{r}}^{2}\right) / 2
$$

with

$$
\Delta W_{\left(\alpha=90^{\circ}\right)}=W_{\mathrm{p}}+W_{\mathrm{d}}
$$

where $W_{\mathrm{p}}$ and $W_{\mathrm{d}}$ are the energy needed to plastify the shot peened surface layers and the dissipated energy during the impact (by vibrations, superficial heating, etc.), respectively. The energy transmitted by plastic deformation to the treated material can be expressed as:

$$
W_{\mathrm{p}}=K \Delta W=m V_{\mathrm{i}}^{2}\left(1-e_{\mathrm{r}}^{2}\right) K / 2
$$

where $K$ is an efficiency coefficient defined as the ratio of energy transmitted to the treated material to the supplied total initial energy. Generally, it is about $0.8-0.9$ for mechanical impacts [33].

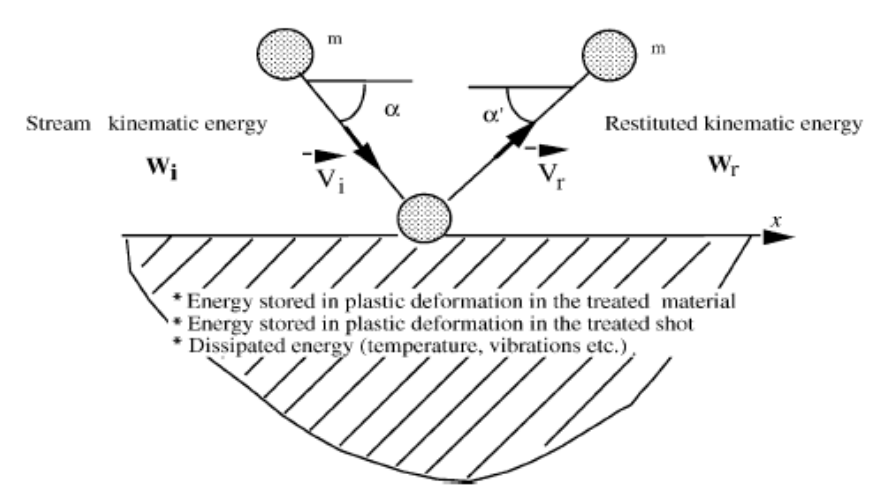

Fig. 1. Energy transmitted during contact shot/material [27]

\subsection{Two-dimensional axisymmetric model [23]}

Based on software ADINA 7.1, Schiffner et al. [23] used a dynamic two-dimensional (2D) axisymmetric finite element model to simulate the perpendicular impact of a single elastic sphere on an elastic-plastic workpiece, as shown in Fig. 2. The shot is defined as the target and the workpiece is defined as the contactor which is opposite to perception. The govern- 
ing equations for the shot and the workpiece which are coupled by the contact conditions between the shot and workpiece are:

for the shot

$$
\begin{aligned}
& \underline{\underline{M}}_{s} \underline{\ddot{d}}_{s}+\underline{\underline{K}}_{s} \underline{d}_{s}=\underline{R}_{s} \\
& \underline{d}_{s}(t=0)=0 \\
& \underline{\dot{d}}_{s}(t=0)=v_{0}
\end{aligned}
$$

for the workpiece

$$
\begin{aligned}
& \underline{\underline{M}}_{w} \underline{\ddot{d}}_{w}+\underline{\underline{K}}_{w} \underline{d}_{s}=\underline{R}_{w} \\
& \underline{d}_{w}(t=0)=0 \\
& \underline{\dot{d}}_{w}(t=0)=0
\end{aligned}
$$

Note that damping has been neglected in Eqs. (1) and (2). Implicit time integration method is used to solve the above governing equations. Due to the high expected strains, high order axisymmetric elements must be used in this method.

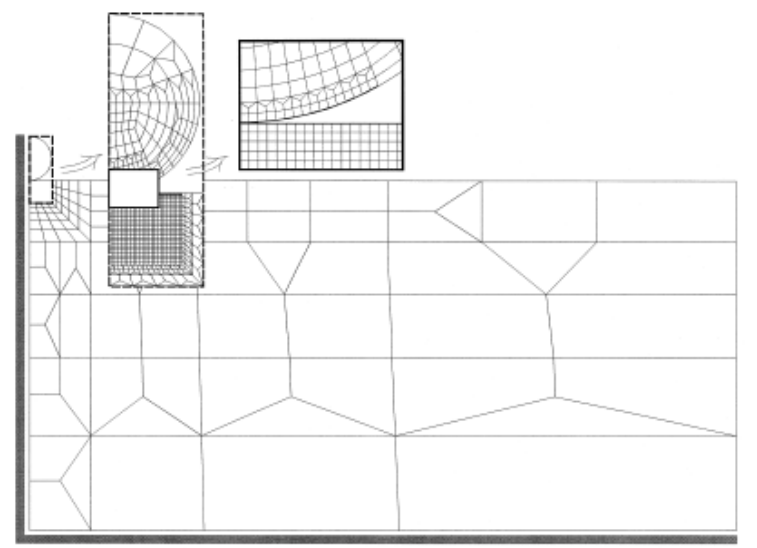

Fig. 2. Discretization of the axisymmetric FE model [23]
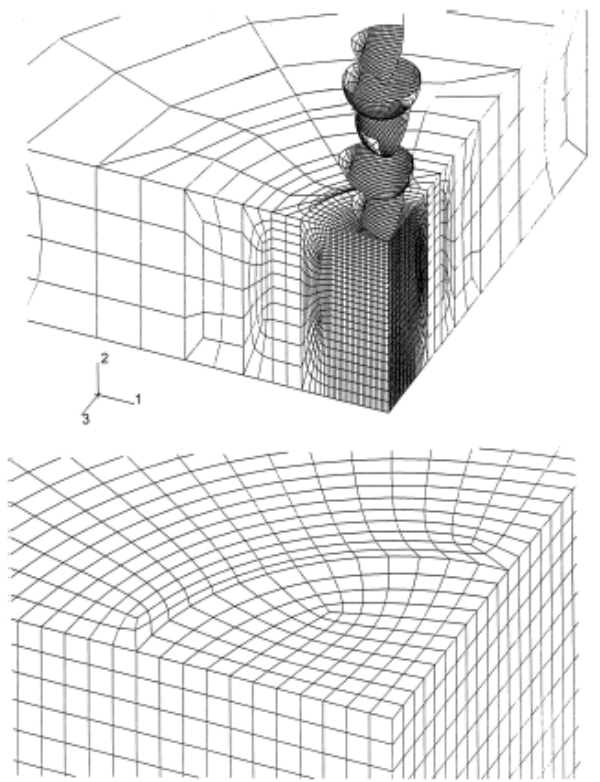

Fig. 3. 3D finite element model for the determination of residual stresses due to the multiple impact of shots [22]

\subsection{D FE method [22]}

Using ABAQUS Explicit Code, Guagliano [22] used a 3D finite element, as shown in Fig. 3, to calculate the residual stress field induced by multiple impacts on an elasto-plastic body. The relationship between Almen intensity and residual stress field is considered. The Almen intensity is defined as

$$
h=\frac{3 M l^{2}}{2 E b h^{3}}
$$

where $l$ is the reference distance for measuring Almen intensity. $b$ is the strip width. $h$ is the strip thickness. Note that the effect of the transverse curvature is not considered in this model.

\subsection{D FE method for dynamic model [28, 37]}

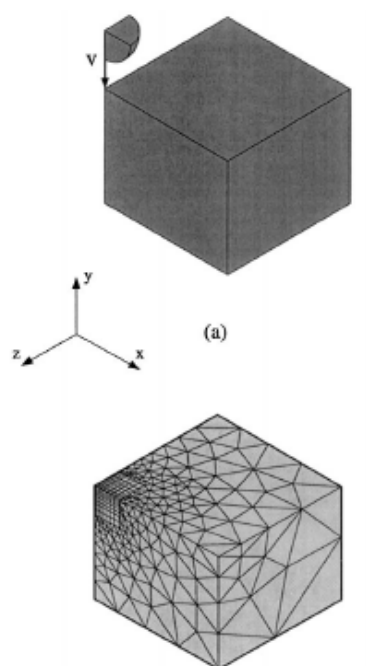

(c)

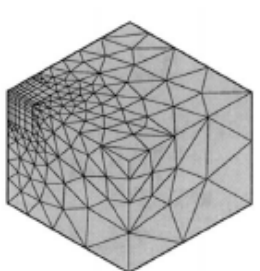

(b)

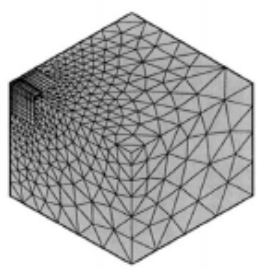

(d)
Fig. 4. Geometry and discretized models used in the single-shot model: (a) one-quarter of geometry, and (b-d) three discretized geometries of target with different mesh densities. [37]

Based on commercial finite element code ANSYS 5.3, two models are considered to study the effect of shots impinging a metallic target at normal incidence. The first is concerned with a single shot and the second with twin shots. Due to the symmetry, only a quarter of the single shot model was discretized, as depicted in Fig. 4a. Both eight-noded brick and four-noded tetrahedral finite elements were used to discretize the target. Convergence tests were conducted using the meshes depicted in Fig. 4b-Fig.4d. Contact elements were used to model the shot/target interface. The three dimensional contact elements adopt a contact node-target segment approach in conjunction with the penalty function method. The contact nodes were created on the top surface of the peened target around the common normal. The target segments were generated only on the lower half of the shot surface (Fig. 4), since it was anticipated that the contact would take place only in that area. The elastic Coulomb law was used. 


\subsection{Prediction models of stress, deformation and sur- face integrity [27]}

Frija et al. [27] numerically studied the simulation method of the shot peening process by using energy equivalence between the dynamic impact and a static indentation of a peening shot in the treated surface. Their model is able to evaluate the residual stress, the plastic deformation profiles and the surface damage.

In their model, the shot is supposed to be a rigid sphere. The mechanical behaviour of the subjected material is assumed to be elastic-plastic coupled with damage, using an integrated form of the Lemaitre and Chaboche model. The shot peening loading is simulated by a static indentation, obtained by an energy equivalence with the dynamic impact. The whole simulation procedure is shown in Fig. 5.

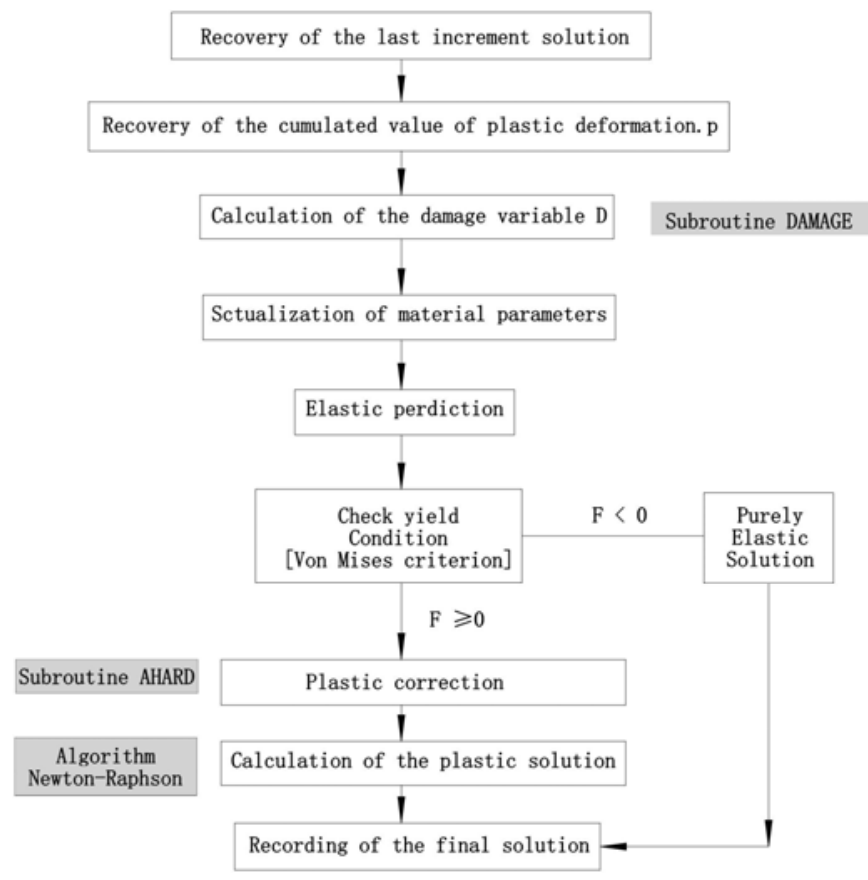

Fig. 5 Flowchart of the calculation [28]

\section{Conclusion}

The criterion to reasonably select the parameters for controlling the shot peening process is of great value for metal sheet forming. The advances of computing techniques make it possible to perform shot peening operations in a comprehensive simulation environment. Before actual operations, one can simulate the critical machining characteristics such as residual stress, plastic deformation firstly. Controlling parameters optimization and selection procedures are then carried out to ensure the process quality. In this paper, the existing numerical techniques are presented to model the shot peening process. These models provide general information about the relations between the process performance and the process parameters. They are the basis to simulate the actual cases and to optimal select the parameters for improving the process performance.

\section{References}

1. R. Fathallah, H. Sidhom, C. Braham, L. Castex, Effect of surface properties on high cycle fatigue behaviour of shot peened ductile steel. Mater. Sci. Technol. 19, 1050-1056 (2003)

2. B. Gentil, M. Desvignes, L. Castex, Analyse des surfaces grenaillées: fissuration, rugosité et contraintes résiduelles Shot peened surface analysis: cracks, roughness and residual stresses. Mater. Technol. 75, 493-497 (1987)

3. M. Desvignes, Influence du grenaillage de précontrainte sur la tenue en service de l'acier 35CD4, Thèse de Doctorat de l'ENSAM, (1987)

4. R. Ahmed, Etude de la creation des fissures en surface de lacier 35CD4lors du grenaillage de precontrainte, memoire de DEA mecanique appliquee a la construction. ENSAM, Paris (1987)

5. L. Wagner, Mechanical surface treatments on titanium, aluminum and magnesium alloys. Mater. Sci. Eng. A 263, 210-216 (1999)

6. N. Sidhom, A. Laamouri, R. Fathallah, C. Braham, H.P. Lieurade, Fatigue strength improvement of $5083 \mathrm{H1} 1 \mathrm{Al}$ alloy T-welded joints by shot peening: experimental characterization and predictive approach. Int. J. Fatigue 27, 729-745 (2005)

7. S. Kyriacou, Shot Peening Mechanics: A Theoretical Study. 6th ed., ICSP, 505-516 (1996)

8. S.A. Meguid, Mechanics of shot peening. Ph.D. Thesis, UMIST, UK (1975)

9. Y.F. Al-Obaid, A rudimentary analysis of improving fatigue life of metals by shot peening. J. Appl. Mech. 57, 307-312 (1990)

10. H. Guechichi, L. Castex, J. Frelat, G. Inglebert, Predicting residual stresses due to shot peening. In: A. Meguid, Editor, Impact Surface Treatment, Elsevier Applied Science Publishers, 11-22 (1986)

11. J. Zarka, J. Casier, Mechanics Today, Pergamon Press, Nemat-Nasser, 6 (1979)

12. M.T. Khabou, L. Castex, G. Inglebert, Effect of material behaviour law on the theoretical shot peening results. Eur. J. Mech. A/Solids 9, 537-549 (1989)

13. R. Fathallah, G. Inglebert, L. Castex, Prediction of plastic deformation and residual stresses induced by shot peening in metallic parts. Mater. Sci. Technol. 14, 631-639 (1998)

14. Y.F. Al-Obaid, Shot peening mechanics: experimental and theoretical analysis. Mech. Mater. 19, 251-260 (1995)

15. M. Kobayashi, T. Matsui, Y. Murakami, Mechanics of creation of compressive residual stress by shot peening. Int. J. Fatigue 20, 351-357 (1998)

16. S.T.S. Al-Hassani, Mechanical aspects of residual stress development in shot Peening. In: Proceedings of the First International Conference on Shot Peening, 583-602 (1981)

17. H. Wohlfahrt, The influence of peening conditions on the resulting distribution of residual stress. In: Proceedings of the Second International Conference on Shot peening, Chicago, USA, 316-331 (1984)

18. S. Kyriacou, Shot peening mechanics, a theorical study. In: Proceedings of the Sixth International Conference on Shot Peening, ICSP6, (1996) 
19. C. Hardy, C.N. Baronet, G.V. Tordion, The elasto-plastic indentation of a half-space by a rigid sphere. Int. J. Numer Methods Eng. 3, 451-462 (1971)

20. J. Edberg, L. Lindgren, K. Mori, Shot peening simulated by two different finite element formulations. In: Shen S, Dawson E, editors.Simulation of materials processing: theory, methods and applications-NUMIFORM95, 425430 (1995)

21. S.T.S. Al-Hassani, K. Kormi, D.C. Webb, Numerical simulation of multiple shot impact. In: Proceedings of the 7th international conference on shot peening, Warsaw, Poland, 217-227 (1999)

22. M. Guagliano, Relating Almen intensity to residual stresses induced by shot peening: a numerical approach. J. Mater. Proc. Technol. 110, 277-286 (2001)

23. K. Schiffner, C.D. Helling, Simulation of residual stresses by shot peening. Comput Struct 72, 329-340 (1999)

24. S. Baragetti, Three-dimensional finite element procedures for shot peening residual stress field prediction. Int. J. Comput Appl. Technol 14, 51-63 (2001)

25. D. Deslaef, E. Rouhaud, S. Rasouli-Yazdi, 3D finite element models of shot peening processes. Mat. Sci. Forum 347-349, 241-246 (2000)

26. E. Rouhaud, D. Deslaef, Influence of shots' material on shot peening, a finite element model. Mat. Sci. Forum 404-407, 153-158 (2002)

27. M. Frija, T. Hassine, R. Fathallah, C. Bouraoui, A. Dogui, Finite element modelling of shot peening process: Prediction of the compressive residual stresses, the plastic deformations and the surface integrity. Mater. Sci. Technol. A 426(1-2), 173-180 (2006)

28. S.A. Meguid, G. Shagal, J.C. Stranart, Finite element modelling of shot-peening residual stresses. J. Mater. Proc. Technol. 92-93, 401-404 (1999)

29. A. Levers, A. Prior, Finite element analysis of shot peening. J. Mater. Proc. Technol. 80-81, 304-308 (1998)

30. M. Meo, R. Vignjevic, Finite element analysis of residual stress induced by shot peening process. Adv. Engin. Soft. 34(9), 569-575 (2003)

31. G.H. Majzoobi, R. Azizi, N.A. Alavi, A threedimensional simulation of shot peening process using multiple shot impacts. J. Mater. Proc. Technol. 164-165, 1226-1234 (2005)

32. T. Hong, J.Y. Ooi, B. Shaw, A numerical simulation to relate the shot peening parameters to the induced residual stresses. Eng. Failure Anal. 15(8), 1097-1110 (2008)

33. W. Johnson, Impact Strength of Materials. Arnold, London, (1972)

34. R. Clausen, Ermittlung von Einflussgressen beim Kugelstrahlen durch Einzelkornversuche. In: Proceedings of the First International Conference on Shot Peening, 279285 (1981)

35. K. Iida, Dent and affected layer produced by shot peening. Second International Conference on Shot Peening, Chicago, USA, 217-227 (1984)

36. J. Edberg, L. Lindgren, K. Mori, Shot peening simulated by two different finite element formulations. In: Shen, Dawson (Eds.), Simulation of Materials Processing: Theory, Methods and Applications, Balkema, Rotterdam, 425-430 (1995)

37. S.A. Meguid, G. Shagal, J.C. Stranart, J. Daly, Three- dimensional dynamic finite element analysis of shotpeening induced residualstresses. Finite Elem Anal Des 31, 179-191 (1999)

38. S.A. Meguid, G. Shagal, J.C. Stranart, 3D FE analysis of peening of strain-rate sensitive materials using multiple impingement model. Int. J. Impact Eng. 27, 119-134 (2002)

39. K. Han, D. Peric, A.J.L. Crook, D.R.J. Owen, A combined finite/discrete element simulation of shot peening processes. Part I: Studies on 2D interaction laws. Eng. Comput 17, 593-619 (2000)

40. K. Han, D. Peric, D.R.J. Owen, J. Yu, A combined $f i-$ nite/discrete element simulation of shot peening processes. Part II: 3D interaction laws. Eng. Comput. 17, 680-702 (2000)

41. K. Han, D.R.J. Owen, D. Peric, Combined finite/discrete element and explicit/implicit simulation of peen forming process. Eng. Comput. 19, 92-118 (2002)

42. S. Shen, Assessment, Development and Validation of Computational Fracture Mechanics Methodologies and Tools for Shot-peened Materials Used in Rotorcraft Principal Structural Elements [S.I.], (2004)

43. I. Lillamand, Cyclic modelling of the mechanical state produced by shotpeening. Fatigue Fract. Eng. Mater. Struct. 24, 93-104 (2001)

44. H. Guechichi,, L. Castex, Fatigue limits prediction of surface treated materials. J. Mater. Proc. Technol. 172, 381-387 (2006)

45. A.S. Franchim, C.V. De, D.N. Travessa, M.N. De, Analytical modelling for residual stresses produced by shot peening. Mater. Des., (In Press) Accepted Manuscript. (2008) 